\title{
A serine protease from the midgut of the bumblebee, Bombus ignitus (Hymenoptera: Apidae): cDNA cloning, gene structure, expression and enzyme activity
}

\author{
Young Moo CHOO ${ }^{1}$, Kwang Sik LEE ${ }^{1}$, Hyung Joo YOON ${ }^{2}$, Sang Beom LEE ${ }^{2}$, Ji Hyeon KIM ${ }^{3}$, Hung Dae SOHN ${ }^{1}$ and \\ BYUNG RAE JIN ${ }^{1 *}$ \\ ${ }^{1}$ College of Natural Resources and Life Science, Dong-A University, Busan 604-714, Korea \\ ${ }^{2}$ Department of Agricultural Biology, National Institute of Agricultural Science and Technology, Suwon 441-100, Korea \\ ${ }^{3}$ Dept. of Chemical \& Biochemical Engineering, Dongguk University, Seoul 100-715, Korea
}

Key words. Apidae, baculovirus expression vector, Bombus ignitus, bumblebee, cDNA cloning, enzyme, expression, gene structure, serine protease

\begin{abstract}
A serine protease gene was cloned from the bumblebee, Bombus ignitus. The B. ignitus serine protease (BiSP) gene spans $1702 \mathrm{bp}$ and consists of four introns and five exons coding for 250 amino acid residues. Southern blot analysis of genomic DNA suggested that BiSP gene is a single copy gene. The cDNA encoding BiSP was expressed as a 28 -kDa polypeptide in baculovirusinfected insect cells and the recombinant BiSP showed activity in a protease enzyme assay. BiSP was specifically expressed in the midgut of $B$. ignitus queens, males, and workers, suggesting that the BiSP is a gut enzyme involved in the digestion of dietary proteins.
\end{abstract}

\section{INTRODUCTION}

Serine proteases are major insect gut enzymes involved in the digestion of dietary proteins (Lehane et al., 1998; Paskewitz \& Gorman, 1999; Gorman et al., 2000; Yan et al., 2001; Barrett et al., 2003). The midgut digestive enzymes are secreted in response to increased protein content in the gut, and their levels in the lumen change throughout the digestion process. Several insect serine protease genes have been identified from the midgut and these are presumed to be involved in the digestion of dietary protein (Lehane et al., 1998; Zhu \& Baker, 2000; Yan et al., 2001; Nakazawa et al., 2004; Li et al., 2005; Zhu et al., 2005). In addition, an insect digestive enzyme, Bombyx mori serine protease, showed antiviral activity against $B$. mori nucleopolyhedrovirus at the initial site of viral infection (Nakazawa et al., 2004). Serine proteases are also known to play critical roles in several biological processes such as blood coagulation, immune responses, signal transduction, hormone activation and development (Nakajima et al., 1997; Gorman et al., 2000; Barrett et al., 2003; Herrero et al., 2005; Jiang et al., 2005). These serine proteases seem to be involved in various biological functions, but the roles of serine proteases in bees are poorly understood.

In this study, the serine protease gene in the bumblebee, Bombus ignitus, was cloned in order to provide some basic information needed to determine the possible function/role(s) of serine proteases; future studies would then be aimed at determining the biological functions of serine proteases on the growth and development of bum- blebee. This paper describes the cDNA cloning and characterization of a midgutspecific serine protease of $B$. ignitus (BiSP). The distribution of BiSP was determined by transcriptional and translational levels among queen, male, and worker animals of $B$. ignitus. The BiSP cDNA was also expressed functionally in baculovirus-infected insect cells, and the recombinant serine protease assayed for enzyme activity.

\section{MATERIAL AND METHODS}

\section{Animals}

The bumblebee, Bombus ignitus, was reared under artificial conditions as described previously (Yoon et al., 2002, 2004).

cDNA library screening, nucleotide sequencing and data analysis

The cDNA library used in this study was constructed using whole bodies of B. ignitus workers (Choi et al., 2006). The clones harbouring cDNA inserts were randomly selected and sequenced to generate the expressed sequence tags (ESTs). The plasmid DNA was extracted with the Wizard mini-preparation kit (Promega, Madison, WI). Nucleotides sequences were determined using a BigDyeTerminator cycle sequencing kit in an automated DNA sequencer (Genetic Analyzer, model 310; Perkin-Elmer Applied Biosystems, Foster City, CA). The sequences were compared using the DNASIS and BLAST programs provided by the NCBI (http://www.ncbi.nlm.nih.gov/ BLAST). GenBank, EMBL and SwissProt databases were searched for sequence homology using a BLAST algorithm program (Altschul et al., 1997). MacVector (ver. 6.5, Oxford Molecular Ltd., Oxford, UK) was used to align the amino acid sequences of insect serine protease.

\footnotetext{
* Corresponding author; e-mail: brjin@dau.ac.kr
} 


\section{Genomic DNA isolation, PCR of the BiSP gene and Southern} blot analysis

Genomic DNA was extracted from the midgut tissues of $B$. ignitus workers using a Wizard $^{\mathrm{TM}}$ Genomic DNA Purification Kit, according to the manufacturer's instructions (Promega). The primers used for amplification of the genomic DNA encoding the BiSP were 5'-ATGTTCACTCTGAGCGCT TCA-3' for the translational start region and 5'TCAGTTTCGTTCATAAGATAC-3' for the 3' non-coding region, and were based on the $B i S P$ cDNA cloned in this study. After a 35 -cycle amplification $\left(94^{\circ} \mathrm{C}\right.$ for $30 \mathrm{~s} ; 48^{\circ} \mathrm{C}$ for $40 \mathrm{~s}$; $72^{\circ} \mathrm{C}$ for $2 \mathrm{~min}$ ), PCR products were ethanol precipitated, centrifuged at $10,000 \times g$ for $15 \mathrm{~min}$, and rinsed with $70 \%$ ethanol. These DNAs were then analyzed using 1.0\% agarose gel electrophoresis. The PCR products for sequencing were cloned into pGem-T vector (Promega). The construct was transformed into Escherichia coli TOP10F' cells (Invitrogen, Carlsbad, CA). The nucleotide sequence was determined as described above.

Genomic DNA extracted from the midgut tissues of B. ignitus was digested with ApaI, BamHI or EcoRI, and electrophoresed in a $1.0 \%$ agarose gel. The DNA from the gel was transferred onto a nylon blotting membrane (Schleicher \& Schuell, Dassel, Germany) and hybridized at $42^{\circ} \mathrm{C}$ with a probe in hybridization buffer containing $5 \times \mathrm{SSC}, 5 \times$ Denhardt's solution, $0.5 \%$ SDS, and $100-\mu \mathrm{g} / \mathrm{ml}$ denatured salmon sperm DNA. The 750 bp BiSP cDNA clone was labeled with $\left[\alpha-{ }^{32} \mathrm{P}\right] \mathrm{dCTP}$ (Amersham, Arlington Heights, IL) using the Prime-It II Random Primer Labeling Kit (Stratagene, La Jolla, CA) for use as a hybridization probe. After hybridization, the membrane filter was washed three times for $30 \mathrm{~min}$ each in $0.1 \% \mathrm{SDS}$ and $0.2 \times \mathrm{SSC}(1 \times \mathrm{SSC}$ is $0.15 \mathrm{M} \mathrm{NaCl}$ and $0.015 \mathrm{M}$ sodium citrate) at $65^{\circ} \mathrm{C}$ and exposed to autoradiography film.

\section{Expression of recombinant BiSP protein}

A baculovirus expression vector system (Je et al., 2001), using the Autographa californica nucleopolyhedrovirus (AcNPV) and an insect cell line Sf9, was employed for the production of recombinant BiSP protein. A cDNA fragment containing the full $B i S P$ open reading frame (ORF) was excised from pBlueScript-BiSP by digestion with BamHI and XhoI and inserted into the same sites of the transfer vector, pBacPAK9 (Clontech, Palo Alto, CA) to express BiSP under the control of the AcNPV polyhedrin promoter. Five hundred nanograms of the construct (pBacPAK9-BiSP) and $100 \mathrm{ng}$ of the AcNPV viral DNA (bApGOZA) (Je et al., 2001) were co-transfected into $1.0-1.5 \times 10^{6} \mathrm{Sf} 9$ cells for $5 \mathrm{~h}$ using the Lipofectin reagent (Gibco BRL, Gaithersburg, MD). The transfected cells were cultivated in TC100 medium (Gibco BRL) at $27^{\circ} \mathrm{C}$ for 5 days. The recombinant AcNPV was propagated in $\mathrm{Sf} 9$ cells and the titer was expressed as plaque forming units (PFU) per milliliter as per standard methods (O'Reilly et al., 1992).

\section{Sample preparation and SDS-polyacrylamide gel electro- phoresis (PAGE)}

Insect $\mathrm{Sf} 9$ cells were mock-infected or infected with the wildtype AcNPV and recombinant AcNPV in a 35-mm diameter dish $\left(1 \times 10^{6}\right.$ cells $)$ at a multiplicity of infection (MOI) of 5 PFU per cell. After incubation at $27{ }^{\circ} \mathrm{C}$, cells were harvested at 3 days post-infection (p.i.). For SDS-PAGE (Laemmli, 1970) of cell lysates, uninfected Sf9 cells and cells infected with virus were washed twice with PBS $(140 \mathrm{mM} \mathrm{NaCl}, 27 \mathrm{mM} \mathrm{KCl}, 8$ $\mathrm{mM} \mathrm{Na}_{2} \mathrm{HPO}_{4}, 1.5 \mathrm{mM} \mathrm{KH} \mathrm{PO}_{4}, \mathrm{pH}$ 7.4) and mixed with protein sample buffer and boiled for $5 \mathrm{~min}$. The total cellular lysates were subjected to $10 \%$ SDS-PAGE. After electrophoresis, gels were fixed and stained with $0.1 \%$ Coomassie brilliant blue R-250.
Tissues were dissected from B. ignitus adults and put in cold PBS containing $1 \mathrm{mM}$ PMSF (phenylmethyl-sulfonylfluoride) and a few crystals of phenylthiourea. After washing, the tissues were homogenized in PBS and the homogenate was centrifuged at $10,000 \times \mathrm{g}$ for $10 \mathrm{~min}$. Supernatant was stored at $-70^{\circ} \mathrm{C}$ until used. The protein samples ( $3 \mu \mathrm{g} / \mathrm{lane})$ were subjected to SDSPAGE as described above. Hemolymph was collected in cold test tubes by puncturing the bodies of $B$. ignitus workers. A few crystals of phenylthiourea were added to the test tubes to prevent melanization. The collected hemolymph was centrifuged at $10,000 \times \mathrm{g}$ for $10 \mathrm{~min}$ to remove hemocytes and cell debris, and the supernatant was stored at $-70^{\circ} \mathrm{C}$ until used. The hemolymph ( $1 \mu 1 /$ lane) was subjected to SDS-PAGE as described above.

\section{Preparation of polyclonal antibody and Western blot analysis}

The recombinant BiSP $(\approx 10 \mu \mathrm{g})$ was electroeluted from the SDS-PAGE gel, mixed with an equal volume of Freund's complete adjuvant (a total of $200 \mu \mathrm{l}$ ) and injected into Balb/c mice. Two successive injections were administered with antigens mixed with equal volumes of Freund's incomplete adjuvant (a total of $200 \mu \mathrm{l}$ ) at 1 -week intervals beginning one week after the first injection. Blood was collected three days after the last injection with antigens only and centrifuged at 13,000 rpm for 5 min. The supernatant, containing the antibodies, was stored at $-70^{\circ} \mathrm{C}$ until used.

Western blot analysis was carried out using an ECL Western blotting analysis system (Amersham Biosciences, Buckinghamshire, UK). The protein samples from several tissues, such as epidermis, fat body, gut (including foregut, midgut, and hindgut), venom gland ( $3 \mu \mathrm{g} / \mathrm{lane})$ and hemolymph $(1 \mu \mathrm{l} / \mathrm{lane})$ were mixed with the sample buffer, boiled for $5 \mathrm{~min}$, and loaded on a $10 \%$ SDS-PAGE gel. The proteins were blotted to a sheet of nitrocellulose transfer membrane (Schleicher \& Schuell). After blotting, the membrane was blocked by incubation in a $1 \%$ bovine serum albumin (BSA) solution, incubated with antiserum solution $(1: 1000 \mathrm{v} / \mathrm{v})$ at room temperature for $1 \mathrm{~h}$ and washed in TBST $[10 \mathrm{mM}$ Tris- $\mathrm{HCl}, \mathrm{pH} 8.0,100 \mathrm{mM} \mathrm{NaCl}$, $0.05 \%(\mathrm{v} / \mathrm{v})$ Tween-20]. The membrane was then incubated with anti-mouse IgG horseradish peroxidase (HRP) conjugate and HRP-streptavidin complex. After repeated washing, the membrane was incubated with ECL detection reagents (Amersham Biosciences) and exposed to autoradiography film.

\section{Determination of protease activity}

BiSP enzyme activity was detected in the gel after SDSPAGE by the method of Kim et al. (1998). Gelatin (0.1\%, w/v, Sigma, St. Louis, MO) dissolved in a $20 \mathrm{mM}$ sodium phosphate buffer ( $\mathrm{pH}$ 7.4) was co-polymerized with $12 \%(\mathrm{w} / \mathrm{v})$ acrylamide, $0.32 \%(\mathrm{w} / \mathrm{v})$ bisacrylamide, and $375 \mathrm{mM}$ Tris- $\mathrm{HCl}(\mathrm{pH} 8.8)$ in order to make a running gel. Then $4 \%(\mathrm{w} / \mathrm{v})$ acrylamide, $0.11 \%$ (w/v) bisacrylamide, and $330 \mathrm{mM}$ Tris- $\mathrm{HCl}(\mathrm{pH} 6.8)$ were used for the stacking gel. The protein samples that were prepared from the cellular lysates of the baculovirus-infected Sf9 cells or $B$. ignitus tissues were mixed with a zymogram sample buffer (0.5 M Tris- $\mathrm{HCl}, \mathrm{pH} 6.8,10 \% \mathrm{SDS}, 20 \%$ glycerol, and $0.5 \%$ bromophenol blue). After the electrophoresis was completed, the gel was incubated for $30 \mathrm{~min}$ at room temperature on a rotary shaker in $50 \mathrm{mM}$ Tris-Cl (pH 7.4), which contained $2.5 \%$ Triton $\mathrm{X}-100$, then incubated in a zymogram reaction buffer $(30$ $\mathrm{mM}$ Tris- $\mathrm{HCl}, \mathrm{pH} 7.4,200 \mathrm{mM} \mathrm{NaCl}, 10 \mathrm{mM} \mathrm{CaCl}_{2}$, and $0.02 \%$ Brij-35) at $37^{\circ} \mathrm{C}$ for $12 \mathrm{~h}$. The gel was stained with Coomassie brilliant blue $(0.5 \%)$ for $30 \mathrm{~min}$ and then destained in destaining solution containing $10 \%$ methanol and $5 \%$ acetic acid. Lytic bands visualized by placing the gels on a view box were then photographed. 


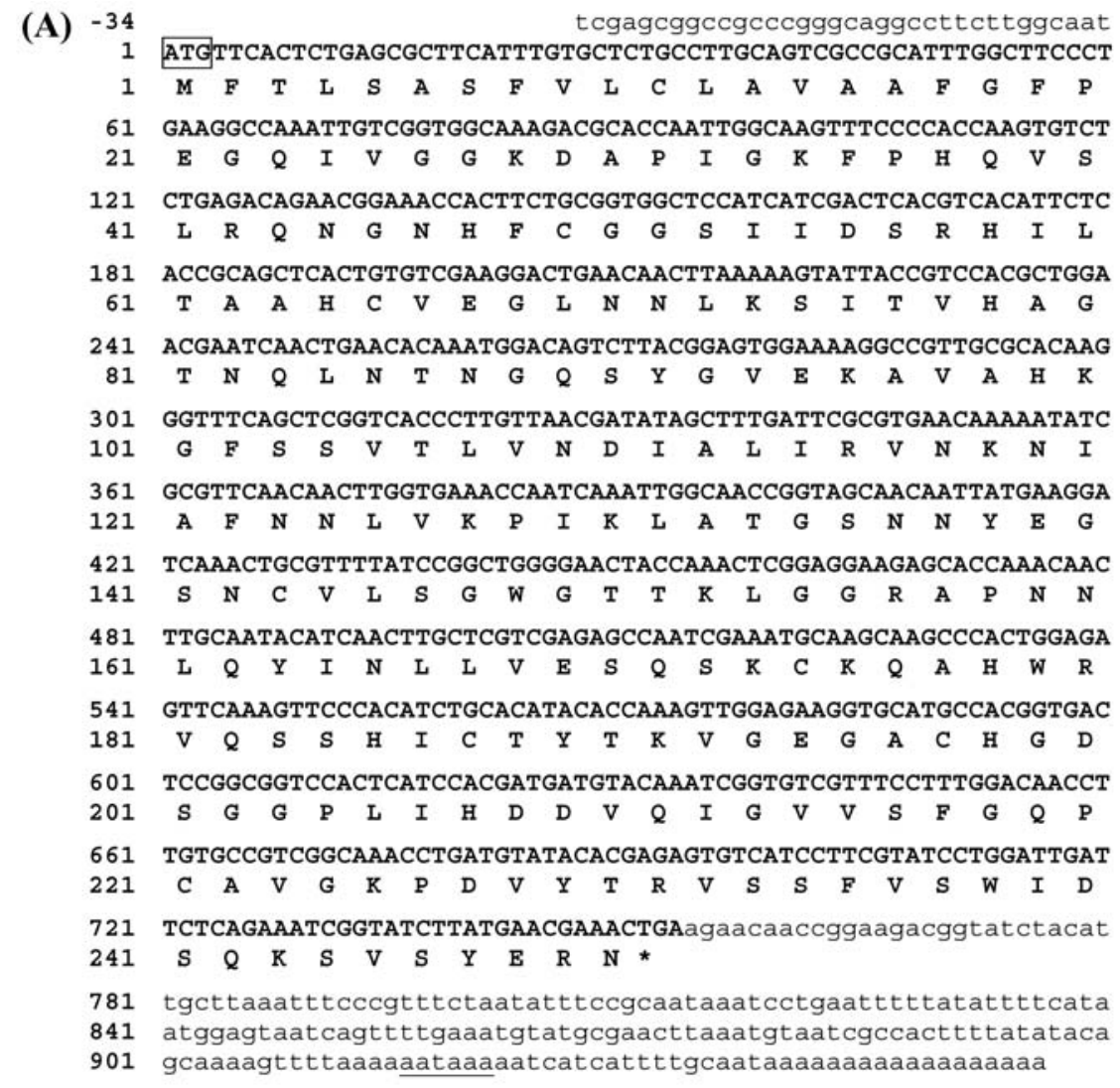

(B)

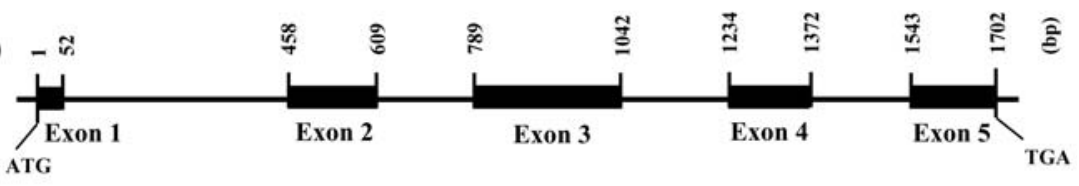

(C)

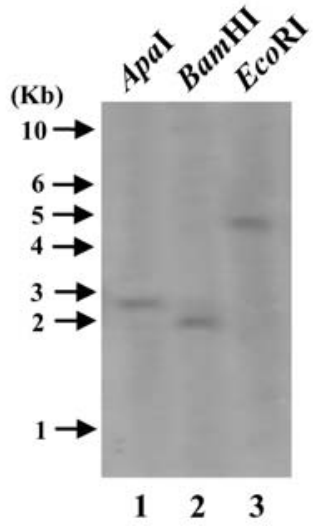

RNA isolation and Northern blot analysis

Queens, males, and workers of B. ignitus were dissected on ice under a stereomicroscope; samples of the epidermis, fat body, gut (foregut, midgut, and hindgut, respectively), and venom gland were collected and washed twice with PBS. Total RNA was isolated from the samples using the Total RNA Extraction Kit (Promega). Total RNA ( $5 \mu \mathrm{g} /$ lane) was separated by $1.0 \%$ formaldehyde agarose gel electrophoresis, transferred onto a nylon blotting membrane (Schleicher \& Schuell) and hybridized at $42^{\circ} \mathrm{C}$ with $\left[\alpha-{ }^{32} \mathrm{P}\right] \mathrm{dCTP}$ (Amersham)-labeled BiSP cDNA probe made with a Prime-It II Random Primer Labeling Kit (Stratagene). Hybridization conditions, fragment labeling,
Fig. 1. cDNA sequence and genomic organization of the BiSP gene. (A) The nucleotide and deduced protein sequence of the $B i S P$ cDNA. The ATG start codon is boxed and the termination codon is indicated by an asterisk. In the cDNA sequence, the polyadenylation sequence is underlined. The GenBank accession number is DQ489309. (B) Organization of the BiSP gene. Numbers indicate the position in the genomic sequences. The GenBank accession number is DQ489308. (C) Southern blot analysis of B. ignitus genomic DNA for the BiSP gene. Genomic DNAs were digested with three restriction enzymes, $A p a I$ (lane 1), BamHI (lane 2) and EcoRI (lane 3), respectively, and hybridized with radiolabeled BiSP cDNA. Size markers are shown on the left.

and filter washing were performed as described for the Southern blot analysis.

\section{RESULTS AND DISCUSSION}

\section{Cloning, sequencing and analysis of BiSP gene}

In a search of $B$. ignitus ESTs, a cDNA was identified that had a high homology with previously reported serine protease genes. The cDNA clone, including the fulllength ORF, was sequenced and characterized. The nucleotide and deduced amino acid sequences of the cDNA encoding BiSP are presented in Fig. 1A. The BiSP cDNA is 990 bp long and contains an ORF of 750 


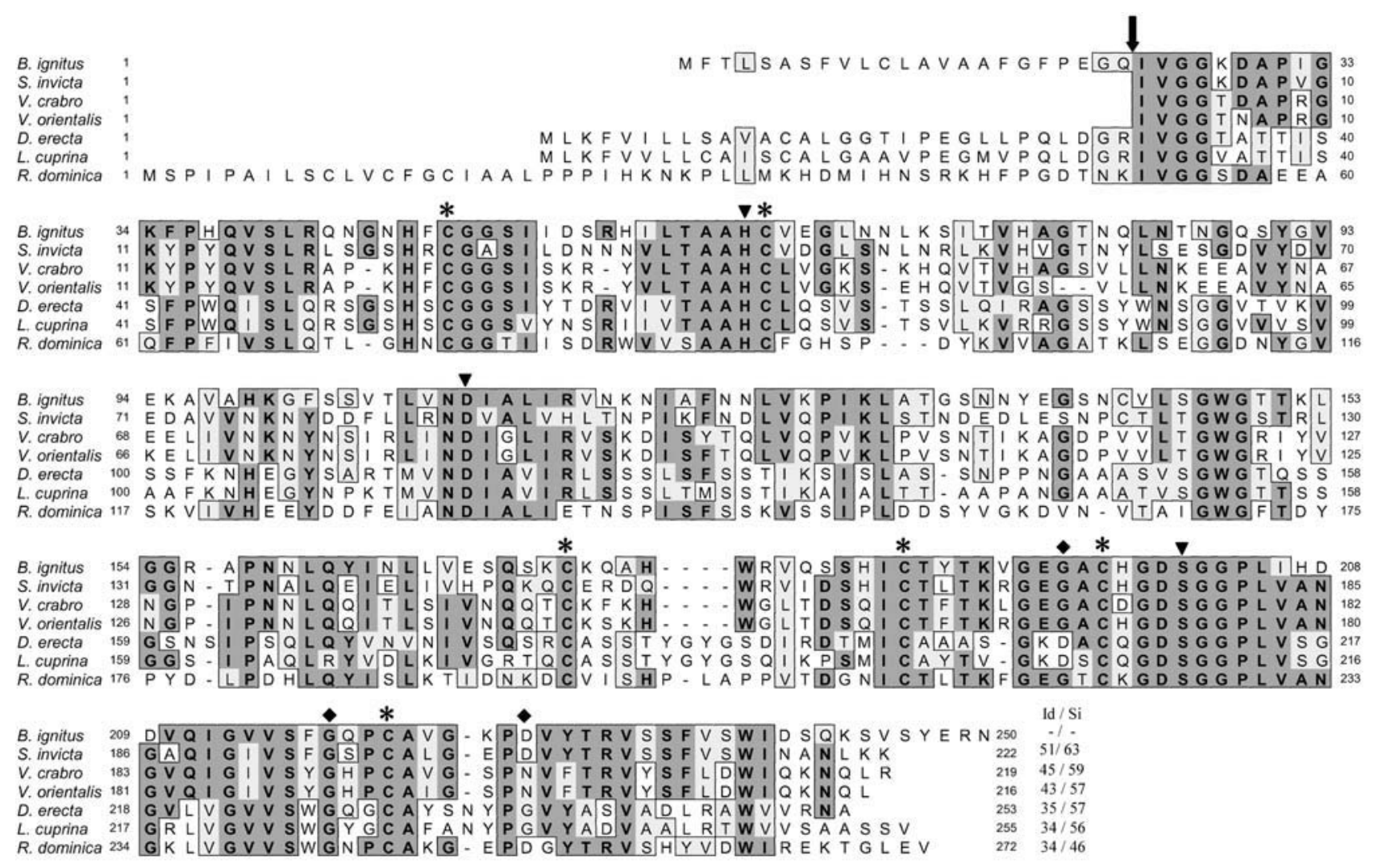

Fig. 2. Comparison of the deduced amino acid sequence of BiSP with that of other serine proteases. Invariant residues are shaded black. The residues of the catalytic triad $(\mathrm{H}, \mathrm{D}, \mathrm{S})$ in BiSP are indicated by solid triangles, and the important determinants of the specificity pocket by solid diamonds. Six conserved cysteine residues are marked by asterisks. The downward arrow indicates the N-terminal residues of the active enzymes. GenBank accession numbers are: Solenopsis invicta (1EQ9-A), Vespa crabro (P00769), Vespa orientalis (P00768), Drosophila erecta (U40653), Lucilia cuprina (U03760) and Rhyzopertha dominica (AF127088). BiSP sequence was used as a reference for the identity / similarity $(\mathrm{Id} / \mathrm{Si})$ values.

nucleotides capable of encoding a 250 amino acid polypeptide. The ORF had both a start (ATG) and stop codon (TAA), indicating that the sequences contain the complete coding region. A putative polyadenylation signal, AATAAA, is located at nucleotide position 916-921.

To characterize the genomic structure of the BiSP gene, a primer set based on the sequences of the BiSP cDNA was designed and a band was amplified from B. ignitus genomic DNA using this primer set. The PCR product was cloned and sequenced. Genomic PCR product sequences were $100 \%$ identical with BiSP cDNA. The organization of the gene is illustrated in Fig. 1B. Comparison of the genomic sequence with the sequence of the cDNA revealed five exons and four introns in the BiSP gene. The sequences at the exon-intron boundaries conformed with consensus eukaryotic splice sites, including an invariant GT at the intron 5' boundary and an invariant AG at its 3' boundary. The genomic DNA size from translation start codon to stop codon was 1702 bp for BiSP.

To determine the copy number of the BiSP gene in the $B$. ignitus genome, genomic DNA was digested with restriction enzymes that do not cut within the BiSP gene, blotted, and then hybridized with the BiSP cDNA. A single hybridizing band was detected with each enzyme, indicating that the BiSP is present as a single copy (Fig. 1C).

A comparison of the deduced amino acid sequence of the BiSP gene with that of other serine protease sequences is shown in Fig. 2. The positions of amino acid residues forming the Asp/His/Ser catalytic triad and the substrate binding pocket and those of the six cysteine residues known to form three disulfide bridges (Kraut, 1977; Lehane et al., 1998; Yan et al., 2001; Herrero et al., 2005; Jiang et al., 2005; Li et al., 2005) are conserved in the sequence of BiSP. The BiSP contains a highly conserved $\mathrm{N}$-terminus (IVGG), which marks the N-terminus of the active enzyme. On the basis of these characteristics, we propose that BiSP is a member of the same family as all other insect serine proteases identified to date. Based on sequence and predicted protein structure similarity, BiSP shows the closest amino acid identity (51\%) with a serine protease of the fire ant Solenopsis invicta.

\section{Expression of BiSP cDNA in baculovirus-infected insect cells}

To assess its expression of the BiSP cDNA, the $750 \mathrm{bp}$ of BiSP cDNA was inserted into a baculovirus transfer vector. The baculovirus transfer vector was then used to generate a recombinant virus expressing BiSP. The transfer vector, pBacPAK9-BiSP, was constructed by 


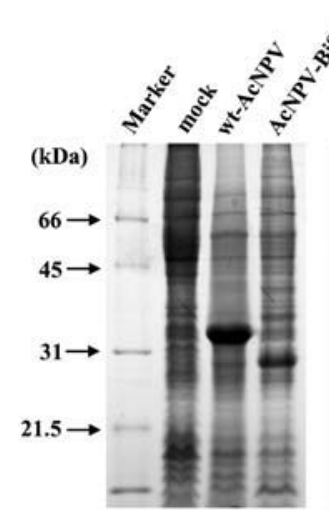

(A)

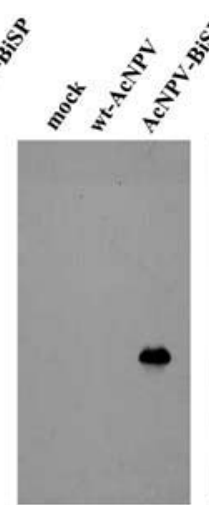

(B)

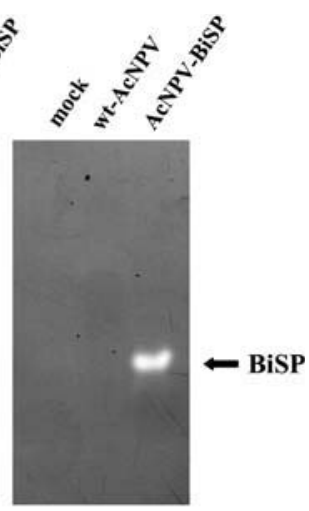

(C)
Fig. 3. SDS-PAGE (A), Western blot analysis (B) and proteolytic activity assay (C) of the recombinant BiSP expressed in baculovirus-infected insect cells. Sf9 cells were mockinfected or infected with wild-type AcNPV and recombinant AcNPV (AcNPV-BiSP) at a MOI of 5 PFU per cell. Cells were collected at 3 days p.i. Total cellular lysates were subjected to $10 \%$ SDSPAGE (A), electroblotted and incubated with recombinant BiSP antibody (B). The same cellular lysates as in panel (A) were separated by $10 \%$ SDSPAGE containing $0.1 \%$ gelatin and the proteins with proteolytic activity were identified as lytic zones (C). The recombinant BiSP is indicated by the arrow on the right side of the panel. Molecular weight standards were used as size markers.

inserting the BiSP cDNA under the control of AcNPV polyhedrin promoter of pBacPAK9 (data not shown). Recombinant AcNPV, which we have termed AcNPVBiSP, was produced in insect Sf9 cells by cotransfection with AcNPV genomic DNA and the transfer vector.

To examine the expression of BiSP cDNA by recombinant virus in insect cells, SDS-PAGE (Fig. 3A) and Western blot analysis (Fig. 3B) were performed to analyze BiSP protein synthesis in the Sf9 cells infected with the recombinant virus. The recombinant BiSP was present as a single band of $28 \mathrm{kDa}$ polypeptide in the cells infected with the recombinant virus, but not in the cells infected with the wild-type AcNPV or mock-infected cells.

In the SDS-polyacrylamide gel containing $0.1 \%$ gelatin, the protein band with proteolytic activity was directly detected as lytic zones ( $\mathrm{Li}$ et al., 2005). The proteolytic activity was detected in a $28 \mathrm{kDa}$ band from the recombinant BiSP virus-infected insect cells (Fig. 3C). This result shows that the BiSP gene is functionally expressed as a $28 \mathrm{kDa}$ polypeptide in baculovirus-infected insect cells. Recent studies have also shown the functional expression of midgut serine protease using the baculovirus system (Herrero et al., 2005; Li et al., 2005).

\section{Tissue distribution of BiSP}

BiSP distribution among $B$. ignitus tissues was investigated at both the transcriptional and translational levels. First, the distribution of BiSP was determined by Northern blot analysis of epidermis, fat body, gut and venom gland. Northern blot analysis showed that a
(A)

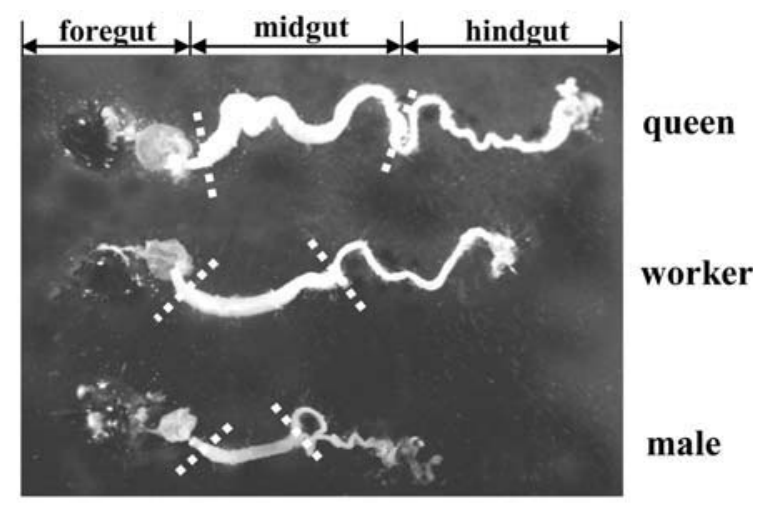

(B)

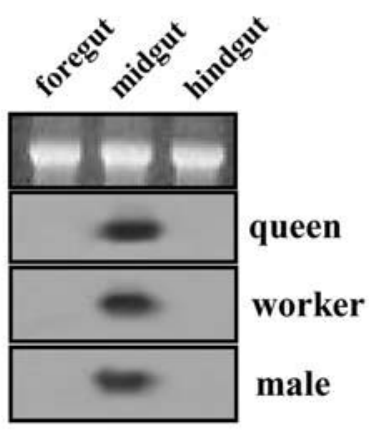

(C)

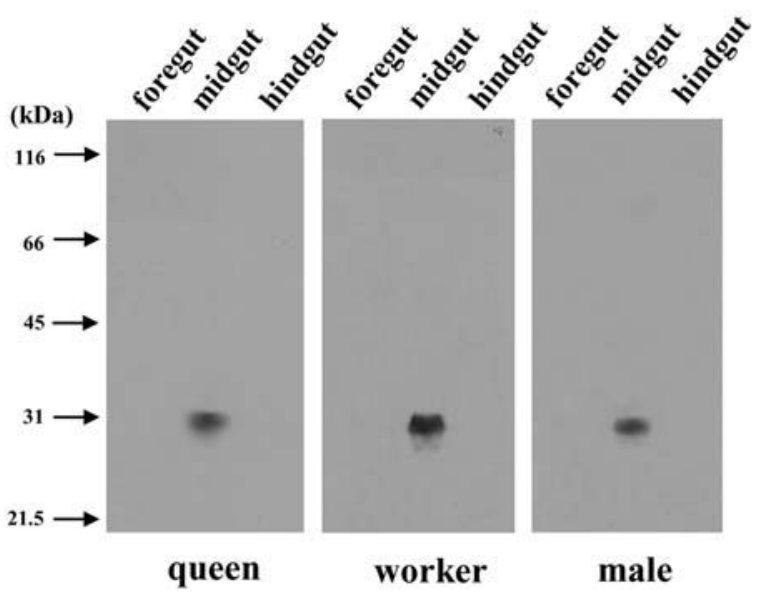

Fig. 4. Distribution of BiSP among three gut regions of $B$. ignitus. (A) Three gut regions of the queen, worker, and male of B. ignitus. (B) Northern blot analysis of BiSP. Total RNA was isolated from foregut, midgut and hindgut, respectively. The RNA was separated by $1.0 \%$ formaldehyde agarose gel electrophoresis, transferred onto a nylon membrane, and hybridized with radiolabeled BiSP cDNA. (C) Western blot analysis of BiSP. The protein sample was collected from foregut, midgut and hindgut, respectively. The protein samples were subjected to $10 \%$ SDS-PAGE, electroblotted and incubated with recombinant BiSP antibody.

hybridization signal was present as a single band in the gut, indicating the gut as a specific site for BiSP synthesis (data not shown). The distribution of BiSP was determined by Northern blot analysis of three different gut regions (Fig. 4A). BiSP was specifically expressed in the midgut of $B$. ignitus queens, males and workers (Fig. 4B).

Next, the distribution of BiSP was analyzed from protein samples of three gut regions using antiserum against BiSP (Fig. 4C). A $28 \mathrm{kDa}$ band corresponding to BiSP was detected only in the midgut by Western blot analysis. 


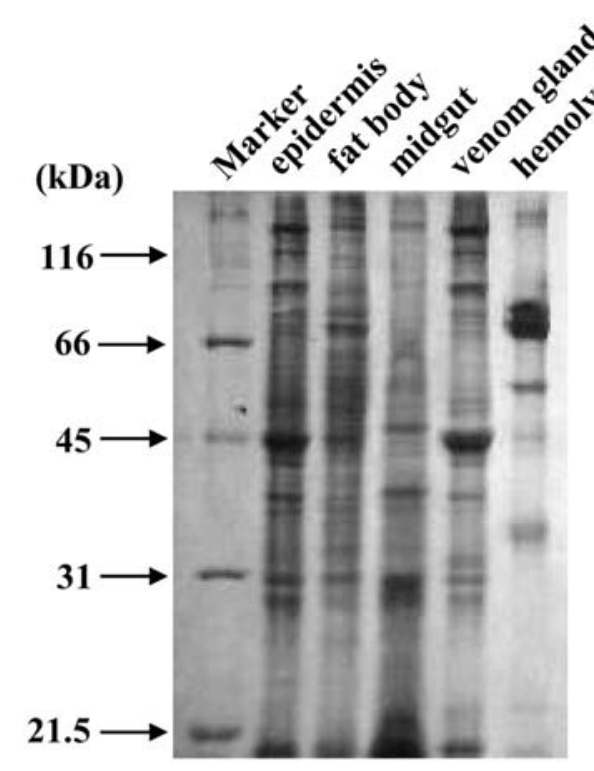

(A)

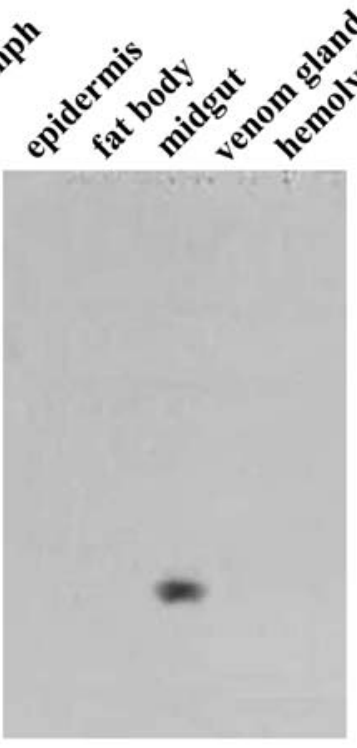

(B)

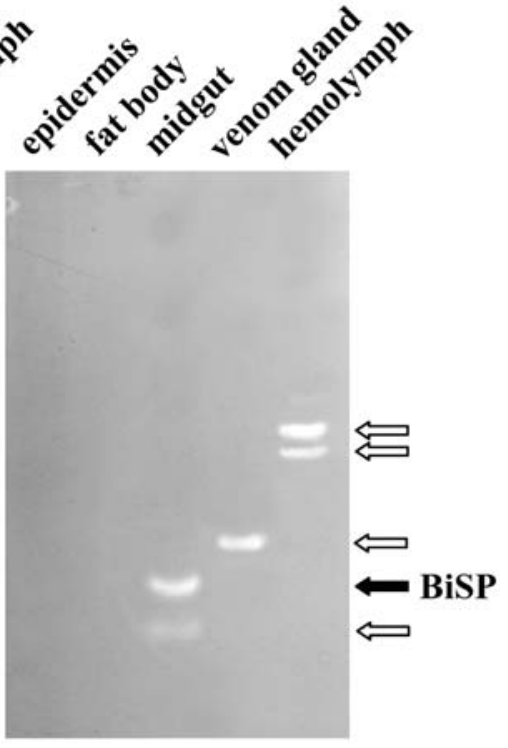

(C)

Fig. 5. Tissue-specific expression of BiSP. The protein samples were collected from epidermis, fat body, midgut, venom gland, and hemolymph of $B$. ignitus worker. The protein samples were subjected to $10 \%$ SDS-PAGE (A), electroblotted and incubated with recombinant BiSP antibody (B). In addition, the protein samples of panel (A) were separated by $10 \%$ SDS-PAGE containing $0.1 \%$ gelatin and the proteins with proteolytic activity were identified as lytic zones (C). The BiSP (solid arrow) and signal bands showing proteolytic activity (open arrows) are indicated on the right side of the panel.

Consistent with the Northern blot analysis, the result of Western blot analysis revealed that BiSP occurs in the midgut of queen, male, and worker of B. ignitus. These results indicate that BiSP expression is shared in the queen, male, and worker animals of B. ignitus.

Furthermore, the tissue specific expression of BiSP was analyzed using protein samples of epidermis, fat body, midgut, venom gland, and hemolymph of B. ignitus worker. Each protein sample was subjected to $10 \%$ SDSPAGE (Fig. 5A) and Western blot analysis (Fig. 5B). A $28 \mathrm{kDa}$ band was detected specifically in the midgut by Western blot analysis, suggesting that the midgut is the primary site where large quantities of BiSP are synthesized for degrading protein absorbed from the diet. The $28 \mathrm{kDa}$ protein band also showed proteolytic activity (Fig. 5C). Western blot analysis and an enzyme assay confirmed a proteolytic activity in the midgut and the presence of $28 \mathrm{kDa}$ BiSP polypeptide. However, protein bands of both $28 \mathrm{kDa}$ and $24 \mathrm{kDa}$ from midgut extracts displayed proteolytic activity in the enzyme assay (Fig. 5C). Thus, the proteolytic activity assay suggests that $B$. ignitus has an additional protease (approximately $24 \mathrm{kDa}$ ) in the midgut. On the other hand, the proteolytic activity in enzyme assay was detected in both venom gland and hemolymph (Fig. 5C). This result suggests that B. ignitus has other protease genes in both venom gland and hemolymph, as well as in midgut. The existence of serine protease in hemolymph and venom gland was observed in several insects (Parkinson et al., 2002; Jiang et al., 2005) and indicated that serine proteases are involved in a wide range of physiological functions (Barrett et al., 2003).

Considering the fact that the midgut in insects is the primary source of the serine protease that functions as a major digestive enzyme (Lehane et al., 1998; Zhu \& Baker, 2000; Yan et al., 2001; Li et al., 2005; Zhu et al., 2005), all our observations strongly support the hypothesis that BiSP is tissue-specific in the midgut of $B$. ignitus, where it would function as a digestive protease. Digestive serine proteases play two critical roles in an insect physiology: digesting dietary proteins for growth and development and inactivating protein toxins and microbial infection ingested as a consequence of feeding (Terra et al., 1996; Nakazawa et al., 2004). Our research has confirmed BiSP as the midgut-specific serine protease of $B$. ignitus, but the involvement of BiSP in defense to microbial infection should be further investigated.

ACKNOWLEDGEMENTS. This work was funded by the Dong-A University Research Fund.

\section{REFERENCES}

Altschul S.F., Madden T.L., Schaffer A.A., Zhang J., Zhang Z., Miller W. \& LipMAN D.J. 1997: Gapped BLAST and PSIBLAST: a new generation of protein database search programs. Nucl. Acids Res. 25: 3389-3402.

Barrett A.J., Rawlings N.D. \& Woessner J.F. 2003: Handbook of Proteolytic Enzymes. Academic Press, New York.

Choi Y.S., Lee K.S., Yoon H.J., Kim I., Sohn H.D. \& Jin B.R. 2006: A bumblebee thioredoxin-like protein gene that is upregulated by a temperature stimulus and lipopolysaccharide injection. Eur. J. Entomol. 103: 291-296.

Gorman M.J., Andreeva O.V. \& PAskewitz S.M. 2000: Sp22D: a multidomain serine protease with a putative role in insect immunity. Gene 251: 9-17.

Herrero S., Combes E., Van Oers M.M., Vlak J.M., De MaAgd R.A. \& BEEKWILDER J. 2005: Identification and recombinant expression of a novel chymotrypsin from Spodoptera exigua. Insect Biochem. Mol. Biol. 35: 1073-1082. 
Je Y.H., Chang J.H., Choi J.Y., Roh J.Y., Jin B.R., O’Reilly D.R. \& Kang S.K. 2001: A defective viral genome maintained in Escherichia coli for the generation of baculovirus expression vectors. Biotechnol. Lett. 23: 575-582.

Jiang H., Wang Y., Gu Y., Guo X., Zou Z., Scholz F., TRenczeK T.E. \& Kanost M.R. 2005: Molecular identification of a bevy of serine proteinases in Manduca sexta hemolymph. Insect Biochem. Mol. Biol. 35: 931-943.

Kim S.H., Chor N.S. \& Lee W.Y. 1998: Fibrin zymography: a direct analysis of fibrinolytic enzymes on gels. Anal. Biochem. 263: 115-116.

KRAUT J. 1977: Serine proteases: structure and mechanism of catalysis. Annu. Rev. Biochem. 46: 331-358.

LAEMMLI U.K. 1970: Cleavage of structural proteins during assembly of the head of bacteriophage T4. Nature 227: $680-685$.

Lehane S.M., Assinder S.J. \& Lehane M.J. 1998: Cloning, sequencing, temporal expression and tissue-specificity of two serine proteases from the midgut of the blood-feeding fly Stomoxys calcitrans. Eur. J. Biochem. 254: 290-296.

Li J., Сhoо Y.M., Lee K.S., Je Y.H., Woo S.D., Кıм I., SohN H.D. \& JIN B.R. 2005: A serine protease gene from the firefly, Pyrocoelia rufa: gene structure, expression, and enzyme activity. Biotechnol. Lett. 27: 1051-1057.

Nakajima Y., Tsuji Y., Homma K. \& Natori S. 1997: A novel protease in the pupal yellow body of Sarcophaga peregrina (flesh fly). J. Biol. Chem. 272: 23805-23810.

Nakazawa H., Tsuneishi E., Ponnuvel K.M., Furukawa S. Asaoka A., Tanaka H., Ishibashi J. \& Yamakawa M. 2004: Antiviral activity of a serine protease from the digestive juice of Bombyx mori larvae against nucleopolyhedrovirus. Virology 321: 154-162.

O'Reilly D.R., Miller L.K. \& LucKow V.A. 1992: Baculovirus Expression Vectors: A Laboratory Manual. W.H. Freeman \& Co., New York.
Parkinson N., Richards E.H., Conyers C., Smith I. \& Edwards J.P. 2002: Analysis of venom constituents from the parasitoid wasp Pimpla hypochondriaca and cloning of a cDNA encoding a venom protein. Insect Biochem. Mol. Biol. 32: 729-735.

Paskewitz S.M. \& Gorman M.J. 1999: Mosquito immunity and malaria parasites. Am. Entomol. 45: 80-94.

Terra W.R., Ferreira C., Jordao B.P. \& Dillon R.J. 1996: Digestive enzymes. In Lehane M.J. \& Billingsley P.F. (eds): Biology of the Insect Midgut. Chapman \& Hall, London, pp. 153-194.

Yan J., Cheng Q., Li C.B. \& Aksoy S. 2001: Molecular characterization of two serine proteases expressed in gut tissue of the African trypanosome vector, Glossina morsitans morsitans. Insect Mol. Biol. 10: 47-56.

Yoon H.J., KIM S.E. \& KIM Y.S. 2002: Temperature and humidity favorable for colony development of the indoorreared bumblebee, Bombus ignitus. Appl. Entomol. Zool. 37: 419-423.

Yoon H.J., Kim S.E., Kim Y.S. \& LeE S.B. 2004: Colony developmental characteristics of the bumblebee queen, Bombus ignitus by the first oviposition day. Int. J. Indust. Entomol. 8: 139-143.

ZHU Y.C. \& BAKER J.E. 2000: Molecular cloning and characterization of a midgut chymotrypsin-like enzyme from the lesser grain borer, Rhyzopertha dominica. Arch. Insect Biochem. Physiol. 43: 173-184.

Zhu Y.C., Liu X., Maddur A.A., Oppert B. \& Chen M.S. 2005: Cloning and characterization of chymotrypsin- and trypsinlike cDNAs from the gut of the Hessian fly [Mayetiola destructor (Say)]. Insect Biochem. Mol. Biol. 35: 23-32.

Received April 26, 2006; revised and accepted June 13, 2006 